\title{
A PERFORMANCE NARRATIVA DO JOGADOR RONALDO COMO FENÔMENO SEXUAL EM UM JORNAL CARIOCA: MULTIMODALIDADE, POSICIONAMENTO E ICONICIDADE
}

\section{THE NARRATIVE PERFORMANCE OF THE FOOTBALLER RONALDO AS A SEX PHENOMENON IN A RIO DE JANEIRO DAILY: MULTIMODALITY, POSITIONING AND ICONICITY}

\author{
Luiz Paulo da Moita Lopes*
}

RESUMO: Por meio do instrumental analítico de uma análise crítica e multimodal do discurso e de teorizações da narrativa e do gênero como performance, a primeira parte do artigo analisa a performance narrativa de masculinidade hegemônica do jogador Ronaldo em um texto jornalístico. A segunda focaliza posicionamentos interacionais de dois homens, gerados em uma entrevista de grupo focal sobre o mesmo texto. Os resultados apontam como esses leitores iconicizam em seus posicionamentos aqueles que aparecem no diário.

PALAVRAS-CHAVE: análise crítica do discurso, multimodalidade, gênero, narrativa, performance.

ABSTRACT: Through the analytical tool of a critical and multimodal analysis of discourse and of the theorizing of narrative and gender as performance, the first part of this paper analyses the narrative performance of hegemonic masculinity of the footballer Ronaldo in a journalistic text. The second part focuses on the interactional positioning of two men, generated in a focus-group interview about the same text. The results show how the positioning of these readers iconicizes those that appear in the newspaper.

KEY-WORDS: critical discourse analysis, multimodality, gender, narrative, performance.

\footnotetext{
* Professor Titular do Programa Interdisciplinar de Pós-graduação em Linguística Aplicada da UFRJ, Ph D em Linguística Aplicada (Universidade de Londres), Pesquisador do CNPq (306756-4) e do Programa Cientistas do Nosso Estado da FAPERJ (E-26/100.575/2007). moitalopes@oi.com.br. Sou grato à Branca Falabella Fabrício (UFRJ) por suas sugestões a uma primeira versão deste artigo.
} 

"É claro que a mídia de massa obviamente faz circular certos tipos de performances masculina e feminina como preferíveis, o que torna desse modo as categorias de gênero mais 'reais'. Em momentos particulares, então, a mídia pode fazer os comportamentos generificados parecerem mais 'naturais', mas quando considerados no decorrer do tempo, as grandes mudanças revelam a própria construção das performances de gênero."

Gauntlett. ${ }^{1}$

\section{INTRODUÇÃO}

A força da mídia na construção da vida social contemporânea não precisa ser mais enfatizada. Em nosso mundo hipersemiotizado (CHOULIARAKI; FAIRCLOUGH, 1999), grande parte dos discursos em que circulamos, de um modo ou de outro, reverberam ou são discursos midiáticos. A mídia vê tudo, fala sobre tudo, e se tornou uma instituição crucial na vida contemporânea. Eventos que ocorrem na esquina da rua em que moramos, por assim dizer, nos chegam por meio da mídia antes que consigamos conversar sobre eles com o vizinho da porta ao lado (THOMPSON, 1998).

A mídia, portanto, desempenha um papel importante na criação de "regimes de verdade" (FOUCAULT, 1979), na confirmação e no questionamento de discursos existentes ou no avanço de novos discursos. É, portanto, crucial na construção da reflexividade na qual nossas sociedades estão envolvidas (GIDDENS; BECK; LASH, 1997). Não surpreende, deste modo, que muitos dos temas que no passado só podiam ser tratados entre quatro paredes, na intimidade, são agora discutidos na mídia. Mais do que a praça pública da antiguidade, a Ágora grega, a mídia se tornou o quarto público, por assim dizer, no qual quase todos os tipos de tópicos são permitidos, incluindo aqueles relacionados à chamada vida privada. Os gêneros e as sexualidades estão naturalmente entre os tópicos favoritos.

\footnotetext{
${ }^{1}$ A tradução dessa epígrafe e das citações neste artigo é de minha autoria.
} 
Isso ocorre não somente porque tais temas vendem bem em uma sociedade de mercado (especialmente, entre outras razões, pelo nosso interesse na produção da verdade sobre o sexo - como diz Foucault, 1988: 146), mas também porque mobilizam discursos relacionados à vida íntima, que são cada vez mais de domínio público - espaço reconfigurado como palco no qual a vida privada é representada publicamente (BAUMAN, 1999).

Nesse contexto, os limites entre o público e o privado se tornaram opacos. Um dos efeitos de tal apagamento de fronteiras é o florescimento do mundo das estrelas na "sociedade do espetáculo" (DEBORD, 1997) na qual vivemos. A vida íntima das celebridades está em toda parte e é um tópico constante da mídia popular em todo mundo. Em tal contexto, um campo importante de análise discursivo-social é, certamente, até que ponto as histórias que constroem as estrelas na mídia replicam/confirmam "narrativas canônicas" (BRUNER, 1990) em domínios socioculturais específicos, principalmente quando vivemos, segundo Martin-Barbero (2003: 14), "um movimento crescente de especialização comunicativa do cultural, agora organizado em um sistema de máquinas produtoras de bens simbólicos ajustados a seus 'públicos consumidores"'. O autor chama ainda a atenção para o fato de que não é só a mídia que faz isso: a escola e a igreja também o fazem na ânsia de ir ao encontro dos seus clientes em um mundo em que todos são ou vendedores ou consumidores.

Levando em conta tais considerações, o foco deste artigo é uma matéria publicada em junho de 2004 (cf. anexo), na seção de esportes do jornal carioca O Dia (um dos mais baratos da cidade), que tematiza uma estrela do futebol internacional, Ronaldo, como um matador de mulheres. $\mathrm{O}$ artigo se debruça sobre os processos de mediação de experiências de masculinidades construídas na performance narrativa de Ronaldo na matéria. Essa é uma seção do jornal que no Brasil se dirige principalmente a leitores projetados masculinos uma vez que é dedicada quase que exclusivamente a questões relacionadas ao futebol (LOURO, 1991; MOITA LOPES, 2002). As questões de gênero, contudo, têm constituído o tema de outras seções do jornal como já mostrei anteriormente (MOITA LOPES, 2006b), o que pode indicar que os editores deste diário estão conscientes, por um lado, do interesse que os leitores têm em tais tópicos como um sintoma de nossas sociedades reflexivas, e, por outro, que os gêneros/as sexualidades são um tema de nossos tempos devido aos desafios que visões tradicionais estão enfrentando atualmente em muitos círculos, em um mundo que exige razões para muitas das histórias que nos contaram no passado sobre quem somos (GIDDENS, 2000; FABRÍCIO; MOITA LOPES, 2004). 
Primeiramente, discuto os construtos teóricos que subjazem ao trabalho, nomeadamente, masculinidade como performance, análise crítica multimodal do discurso, narrativa como performance e posicionamento interacional. A seguir, analiso a performance narrativa da masculinidade de Ronaldo no texto jornalístico. Na segunda parte, o foco é em uma conversa sobre tal performance narrativa por meio de dados gerados em uma entrevista de grupo focal (MORGAN; KRUEGER, 1998; LITOSSELITE, 2003), com o objetivo de compreender como dois homens que são parte da comunidade interpretativa (BRICE-HEATH, 1983) de leitores de O Dia se posicionam interacionalmente em relação à performance narrativa de Ronaldo enquanto conversam sobre ela.

Antes de prosseguir, devo esclarecer que minha análise da matéria jornalística é somente uma leitura possível, baseada em princípios teóricos explícitos. Se é verdade que vivemos em sociedades densamente semiotizadas, compreendo que uma das tarefas daqueles envolvidos com pesquisa no campo da linguagem é colaborar na compreensão dos discursos midiáticos que constroem a vida social. Essa abordagem, porém, não implica que todos os efeitos discursivos do texto analisado são explicitados pela análise que apresento. Analistas e leitores estão situados em comunidades diferentes, têm histórias de vida heterogêneas e projetos políticos e valores diversos. Contudo, na segunda parte do trabalho, ao usar uma entrevista de grupo focal sobre o texto analisado na primeira parte, tento mostrar como leitores masculinos, que são leitores projetados para esse jornal, se posicionam em relação à performance narrativa de masculinidade que Ronaldo desempenha na matéria. A pesquisa relatada, portanto, ao combinar princípios da análise crítica multimodal do discurso com outras metodologias de investigação sobre a prática social de cunho mais etnográfico (CHOULIARAKI; FAIRCLOUGH, 1999), amplia o alcance de minha análise ao desenvolver uma interpretação colaborativa, ao mesmo tempo em que permite estudar o discurso em ação nas práticas sóciodiscursivas, aumentando dessa forma a validade ecológica da investigação (SARANGI, 2002).

\section{UMA TEORIZAÇÃO DAS MASCULINIDADES COMO PERFORMANCE}

No cerne de teorizações discursivas (não-essencialistas) das identidades sociais, está a visão do gênero como performance. Essa ótica tem sua origem na teorização empreendida por Goffman (1959) sobre a natureza social 
do si-mesmo (ou self) que a pesquisa de Butler (1990, 1993 e 2004) vem a desenvolver em relação ao gênero. Apoiada no trabalho de Austin (1962) sobre a teoria dos atos da fala em que esse autor demonstra como fazemos coisas no mundo por meio da linguagem, Butler desenvolve uma teoria da performatividade do gênero, pautando-se em uma visão performativa da linguagem: "a enunciação muda o mundo, trazendo à tona um novo estado social” (KULLICK, 2003: 139). Assim, Butler (1993) argumenta que a enunciação de um gênero específico força tal gênero a existir sob regras e normas, o que leva à criação da performance para tal gênero.

Desse modo, "o gênero mostra-se performativo - constitui a identidade que pretende ser. Assim, o gênero é sempre um fazer, embora não seja um fazer realizado por um sujeito de quem se possa dizer que preexista à ação" (BUTLER, 1990: 25), ou seja, não possuímos características de um gênero que existe antes da performance, mas produzimos nosso gênero continuamente por meio das coisas que fazemos. $O$ gênero como performance é algo que o sujeito faz nos posicionamentos que ocupa, nas narrativas que conta, nos modos de sentar, agir, mover o corpo, aceitar e recusar parceiros sexuais etc.

Dessa forma, podemos considerar as masculinidades como performances que surgem no processo de construção do significado com outros, o que implica entender que os gêneros não preexistem ao engajamento discursivo como um processo homogêneo ou como uma carreira com início, meio e fim que se segue. Isso também significa dizer que é impossível definir a masculinidade como unitária e fixa como se todos os homens compartilhassem uma essência e pudessem ser identificados pelos traços, experiências e interesses que têm em comum (CONNELL, 2000).

Há nessa tradição a influência clara de Foucault, em relação à natureza discursiva das identidades sociais, mas Butler (1990) enuncia sua teorização de forma singular ao mostrar como as repetições de performances de gênero, reguladas por normas cuidadosamente determinadas, acabam por gerar uma "aparência de substância" para o que é dado no aqui e no agora, desessencializando os gêneros. Como esclarece Butler (1990: 33), "o gênero é a estilização repetida do corpo, um conjunto de atos repetidos dentro de um enquadre altamente regulador que congela com o passar do tempo para produzir a aparência de substância, de um modo natural de ser", necessitando ser continuamente reafirmado. Assim, o gênero está sempre sendo fabricado nas práticas discursivas cotidianamente nas nossas performances como homens e mulheres, com base em padrões dominantes do que é ser homem ou mulher (THORNBORROW; COATES, 2005). 


\section{O PORQUÊ DE UMA ANÁLISE CRÍTICA E MULTIMODAL DO DISCURSO DA MÍDIA}

O discurso midiático tem atraído mais e mais atenção (FAIRCLOUGH, 1995; BELL; GARRET, 1998; VAN DIJK, 1998; VAN LEEUWEN; JEWITT, 2002; por exemplo) devido a uma consciência cada vez maior da parte de pesquisadores de que esse tipo de discurso produz efeitos particulares de significados na vida social e de que a mídia contemporânea está extremamente sofisticada em relação às estratégias que usa para agir no mundo social (FAIRCLOUGH, 1992 e 1995). Isso significa, portanto, que as escolhas discursivas envolvidas na escrita de um texto jornalístico ou na edição de um programa de TV etc. envolvem certos propósitos políticoideológicos que operam com visões de mundo e valores específicos tendo em vista leitores e telespectadores específicos. Tem sido amplamente notado que a mídia tradicional desenvolve cada vez mais esse uso estratégico do discurso, incorrendo frequentemente na reprodução do senso comum e de forças conservadoras que representam seus interesses (FAIRCLOUGH, 1995; MOITA LOPES; FABRÍCIO, 2005, por exemplo).

Isso não significa, por outro lado, que a mídia não use a mesma tecnologização discursiva com a possibilidade de desconstruir o senso comum ou de construir o mundo social em outras bases, articulando outras ideologias e possibilitando outros posicionamentos. Martin (s/d), por exemplo, tem chamado a atenção para o que denomina análise positiva do discurso que pode detectar outras ordens do discurso da mídia, que fazem circular discursos alternativos para o senso comum. Essas perspectivas nos alertam que o discurso é sempre ideológico já que todo participante do discurso está implicado nos significados que constrói, revelando seus interesses, valores, agendas políticas e visões de mundo. Não há como escapar desse traço intrínseco do discurso. Isso não quer dizer, no entanto, que todos os significados são aceitáveis. Meu ponto de vista é que vale a pena investigar o discurso midiático com o objetivo, entre outros, de levantar questões éticas sobre os significados que a mídia faz circular: uma questão crucial em um mundo cada vez mais mediado e entrecortado por uma multiplicidade de significados sobre quem somos, valores, projetos políticos etc.

A análise crítica e multimodal do discurso (FAIRCLOUGH, 1995; KRESS; VAN LEEUWEN, 2001, por exemplo) éútil por causa de seu foco nas escolhas multimodais (itens lexicais, interdiscursos, gêneros textuais, cores, fotos, desenhos gráficos etc.) que as pessoas fazem das opções existentes 
dentro do potencial para a significação de uma língua e de outros modos semióticos. Essa abordagem enfatiza a relação explícita entre instrumentos semióticos e a sociedade já que explicita as escolhas empreendidas por escritores, leitores, falantes etc. para explorar tal potencial na construção da vida social. Tal perspectiva me permite mostrar como uma ordem do discurso midiático constrói uma visão particular da masculinidade em $O$ Dia, disponibilizando certos "regimes de verdade" (FOUCAULT, 1979) sobre como os homens são, por meio de meios multimodais, na performance narrativa de Ronaldo. Está implícito aqui a ideia de que certos discursos inscrevem os leitores em posicionamentos particulares, o que não significa dizer que eles necessariamente os aceitem. Essa é uma questão que vou retomar na segunda parte do trabalho.

Fairclough (1995) sugere que focalizemos três dimensões para analisar eventos comunicativos: o texto, a prática discursiva e a prática sociocultural. As práticas discursiva e sociocultural foram brevemente discutidas acima quando tratei das várias mudanças que estamos enfrentando atualmente e do papel da mídia nesse processo. Os elementos constitutivos da prática discursiva serão discutidos ainda mais no início da análise quando vou situar o escritor e os potenciais leitores. A seguir, vou analisar o texto tentando dar conta das escolhas feitas pelo escritor na sua construção, aspectos da produção do texto, assim como dos efeitos possíveis de significado que tais escolhas podem trazer à tona, aspectos da interpretação. Como diz Fairclough (1995), é a prática discursiva que faz a mediação entre o texto e a prática sociocultural. Em termos dos objetivos e das pressuposições de minha análise, é o engajamento discursivo entre leitor e escritor na prática discursiva que dá conta da construção dos significados sobre a masculinidade. Assim, o leitor/analista utiliza as pistas semióticas encontradas no texto e o repertório de significados disponíveis na prática social em relação à performance narrativa construída. No entanto, como já foi dito, a segunda parte desta pesquisa almeja aumentar a validade ecológica dessa análise.

\section{PERFORMANCE NARRATIVA}

Já usei o construto de performance anteriormente para abordar a questão do gênero. Agora me aproprio da noção de performance do modo como tem sido usada em relação à narrativa. Antropólogos e etnógrafos têm se referido ao ato de contar uma história como performance (THORNBORROW; COATES, 2005). As narrativas orais pessoais têm sido abordadas como 
performances no sentido de que contadores no momento de narrar suas histórias estão não só relatando os eventos de uma narrativa (os eventos narrados), mas estão também envolvidos na performance de quem são na experiência de contar a narrativa (o evento de narrar) (BAUMAN, 1986; LANGELLIER, 2001; COUPLAND; GARRET; WILLIAMS, 2005; NORRICK, 2005). Ou, como diz Bauman (1986: 3), “a performance [...], da mesma forma que toda atividade humana é situada, sua forma, significado e funções estão enraizadas em cenas e eventos definidos culturalmente".

Nesse processo, a performance como um fazer ou ação constrói a vida social, o que chama a atenção para a natureza constitutiva das narrativas, uma posição que tem sido continuamente defendida em vários campos das Ciências Sociais (BAUMAN, 1986; BRUNER, 1997; SCHIFFRIN, 1996; SOMERS; GIBSON, 1994, por exemplo). Conforme Langellier (2001: 150) indica, "nesse sentido de performance [...] a narrativa nomeia um lugar onde o social é articulado, estruturado e enfrentado em embates". No evento narrativo, os participantes (contadores e ouvintes) estão construindo a vida social e uns aos outros de modos específicos, que são definidos pelo que os participantes decidem focalizar, pelos posicionamentos que escolhem ocupar e pelo modo como os interlocutores se relacionam com eles na performance. Essa visão implica, portanto, que as performances narrativas podem ser compreendidas como lugares em que as masculinidades também como performances são construídas nos embates pelo significado entre contadores, ouvintes e leitores.

As histórias como performances culturais também podem ser vistas pelo valor icônico que podem ter para os membros de uma comunidade, já que põem em evidência e ajudam a cristalizar valores e ideias preferidos pela comunidade com base no que os protagonistas ou narradores fazem e em como são avaliados no narrar performativo (COUPLAND; GARRETT; WILLIAMS, 2005). ${ }^{2}$ Dessa forma, o contar de certas histórias tem um efeito discursivo na constituição da própria comunidade, assim como o modo como ouvintes legitimam ou reagem a tais narrativas vai depender de como essas correspondem às normas e regras da comunidade, uma vez que "performances são pelas audiências e não somente para as audiências" ou "aqueles que fazem a performance frequentemente direcionam suas performances para grupos específicos" (COUPLAND; GARRETT; WILLIAMS, 2005: 69).

\footnotetext{
${ }^{2}$ Veja também Bauman (1986: 4): "muito comumente, as narrativas são vistas como ícones verbais dos eventos que recontam".
} 
Neste trabalho, utilizo tal teorização para tratar da performance narrativa escrita de masculinidade em um artigo de jornal no qual o protagonista do evento narrado - Ronaldo - é levado a desempenhar uma performance de modo particular. Como será mostrado, um jornalista está contando a história de Ronaldo como um matador de mulheres. Portanto, não é Ronaldo que está fazendo a performance de contar a história, mas é levado a fazer tal performance de masculinidade por meio do narrar de um jornalista. Essa narrativa em seu todo é "um ato de fala performativo que funciona para realizar [ou levar a efeito] o que articula" (THREADGOLD, 2005: 276) diante dos leitores projetados de O Dia. Assim, a análise do texto foca o evento narrado da perspectiva de uma análise crítica e multimodal do discurso, já a análise da conversa gerada no grupo focal se centra no evento de narrar, especificamente "nas funções e resultados emergentes da performance" (BAUMAN, 1986:6) por meio da análise dos posicionamentos interacionais ocupados pelos leitores - participantes do evento discursivo constituído no grupo focal. $\mathrm{O}$ que é de interesse na primeira parte do trabalho, portanto, é enfatizar os significados e estratégias discursivas que são utilizados nessa performance narrativa de modo que posicionamentos interacionais particulares são disponibilizados no jogo entre o narrador, os personagens da narrativa e a audiência ou os leitores projetados.

\section{POSICIONAMENTOS NAS NARRATIVAS}

Posicionamento é um construto teórico que tem usos similares em áreas diferentes de investigação (estudos culturais, antropologia, análise do discurso, psicologia social, conforme indicado em Moita Lopes, 2006c). Em geral, tal construto se refere a como as pessoas estão localizadas no discurso ou na conversa quando estão engajadas na construção do significado com outros.

Na psicologia social (DAVIES; HARRÉ, 1999; HARRÉ; LANGENHOVE, 1999, por exemplo), posicionamento é um construto teórico usado de um modo que parece incorporar os significados que são dados quando as pessoas se engajam no discurso: tanto por aspectos da sócio-história em um nível macro quanto em um nível micro e local no discurso, pelos significados que eles próprios geram, podendo escapar de significados dados. Isso dá conta dos posicionamentos cambiantes, dinâmicos e múltiplos que os participantes podem ocupar nas práticas discursivas ou nas práticas narrativas. Esse fato também enfatiza que as performances de gênero são construídas no aqui e no agora em tais posicionamentos, 
confirmando a aparência de substância que os gêneros têm, o que não quer dizer que tal aparência como performance não possa ser desafiada e confundida. Esse enfoque teórico possibilita entender a existência de performances alternativas de gênero ao passo que também embaralha a compreensão binarista dos gêneros como natural, como está patente em muitas práticas atuais (BUTLER, 1990: 149).

Conforme Davies e Harré (1999: 52) indicam, "com o posicionamento, o foco é no modo por meio do qual as práticas discursivas constituem os falantes e ouvintes de certos modos e ainda, ao mesmo tempo, elas são um recurso por meio do qual falantes e ouvintes podem negociar novas posições", e ser, consequentemente, reposicionados. Diria que o mesmo pode estar operando em práticas narrativas escritas nas quais escritores e leitores podem estar sendo posicionados e reposicionados interacionalmente em novas performances.

$\mathrm{Na}$ análise das práticas narrativas, quero argumentar que o posicionamento é um construto útil para localizar contadores/escritores, ouvintes/ leitores e personagens, uns em relação aos outros nos embates de construção de significado nos quais estão envolvidos. No entender de Davies e Harré (1999:37), “o posicionamento [...] é o processo discursivo pelo qual as pessoas estão localizadas na conversa [ou na interação, mais geralmente, argumentaria] como participantes subjetiva e observavelmente como coerentes em estórias produzidas em conjunto". Portanto, pode ser útil para detectar como os gêneros estão sendo levados a existir no discurso oral (EPSTEIN; JOHNSON, 1998) ou, de acordo com a abordagem performativa seguida aqui, como nos posicionamentos interacionais, as performances de gênero são constituídas nas práticas narrativas. Na primeira parte do trabalho, ao analisar um texto escrito, o argumento é que o posicionamento é útil para compreender como Ronaldo é levado a fazer uma performance de masculinidade ou como é levado a existir performativamente no discurso escrito.

\section{ANALISANDO O TEXTO COMO UMA PERFORMANCE NARRATIVA DE MASCULINIDADE: UMA PERSPECTIVA MULTIMODAL}

Inicio a análise chamando a atenção para a prática discursiva entre o escritor e os leitores projetados na qual a prática narrativa em análise está situada. O jornalista é um homem, Marco Senna, assim como são os outros jornalistas que assinam matérias na seção de esportes deste jornal, na qual a maior parte dos artigos focaliza o futebol. A prática discursiva envolve participantes masculinos, escrevendo e lendo sobre um tópico 
tradicionalmente masculino, o que significa dizer que essa narrativa tem reportabilidade (LABOV, 1972), no sentido de que é contável, ou seja, tem algo a dizer aos leitores que tem como alvo, já que "o que é contável é porque depende de experiências e valores reconhecidos culturalmente" (THORNBORROW; COATES, 2005: 12). Nesse sentido, ler/analisar essa narrativa é ser "interpelado" pelos efeitos discursivos que jornais como $O$ Dia disponibilizam no que se refere a performances narrativas de senso comum sobre masculinidade. Em outras palavras, leitores/analistas estão “implicados na citação de [tais] narrativa[s]" (THREADGOLD, 2005: 277).

Tendo em vista os elementos que constituem a prática sociocultural, não surpreende, portanto, que o texto, como prática discursiva, seja uma performance narrativa de masculinidade hegemônica. $\mathrm{Na}$ análise, tento mostrar os posicionamentos que Ronaldo ocupa em tal performance ao me basear nas pistas semióticas multimodais que indexicalizam tais posicionamentos (WORTHAM, 2001)

Uma rápida olhada na página imediatamente dirige a atenção para o fato de que três quartos são ocupados por fotografias dos personagens que atuam na narrativa (Ronaldo e suas mulheres), e somente um quarto é preenchido com texto. Tal traço é na verdade típico da natureza híbrida e multimodal do jornal todo, que combina textos escritos com textos visuais de uma forma mais intensa do que outros jornais. Por um lado, tal característica advém das facilidades tecnológicas agora mais disponíveis no desktop do computador, mas, por outro, mostra a compreensão, por parte dos editores, da relevância do material visual para os leitores desse jornal em detrimento do texto escrito, talvez pela pouca familiaridade que esses têm com a escrita. A performance narrativa que constrói a masculinidade de Ronaldo é, portanto, multimodal.

A seção de esportes é, na verdade, denominada Ataque (uma palavra que no mundo do futebol descreve o momento no qual o time está combatendo os adversários para marcar gol). O próprio título da seção, portanto, enuncia o que vai ser narrado (um ataque) já que o título da narrativa, MATADOR (em maiúsculas negras), é uma palavra que pertence ao mesmo campo semântico de ataque. É de fato um item lexical usado no futebol para se referir ao atacante. Ronaldo, cuja face ocupa quase a metade da página, está posicionado como o atacante desde o início e tal posicionamento é confirmado pela foto que mostra Ronaldo com a língua de fora como se estivesse pronto para continuar agindo como um matador de sua próxima vítima. A narrativa é também contada com o apoio das fotos das mulheres 
que ele "atacou" até então, com sua conquista mais recente, acariciando seu rosto, ou seja, mais uma mulher cedeu aos ataques dele. Os títulos da seção e da narrativa juntam dois mundos ou dois discursos diferentes (esporte e sexo/amor), chamando a atenção também para a natureza híbrida dos discursos envolvidos na narrativa.

No horizonte dos discursos sexuais mobilizados se situam todas as fotos das mulheres em trajes sensuais e em poses eróticas, acentuando o posicionamento de Ronaldo como um matador de mulheres, as quais, de fato, pediram e gostaram de seu ataque (veja nessa direção a foto com os gestos de carinho de sua conquista mais recente). As fotos das mulheres são legendadas por sentenças, as quais todas, com uma única exceção, colocam as mulheres em relação a ele ou ao ataque dele na performance narrativa de masculinidade. Sintaticamente, elas são predicadas por ele, ou seja, ele as qualifica: "Juliana Ferraz garantiu ter sido amante [ela foi amante] do artilheiro durante dez anos"; "Milene Dominguez foi mulher de Ronaldo durante quase quatro anos e é mãe de Ronald"; "As Ronaldinhas, Nádia e Viviane, tiveram caso com o craque [Foram suas amantes] e formaram uma dupla"; "Mirela, modelo espanhola, foi apenas mais um caso relâmpago"; "Daniela Cicarelli, apresentadora da MTV, é a bola da vez no coração do craque da Seleção"; "Lívia Lemos ganhou a capa da Playboy com texto de apresentação do Fenômeno"; "Suzana Werner foi noiva do jogador [...]". A única que nega ter se rendido a seus ataques é Fernanda Lima, "apesar dos boatos": ela não é predicada por "ele" embora os boatos a desmintam.

Além disso, quase todas são posicionadas nas legendas das fotos como personagens da narrativa que, na verdade, se beneficiaram de seus ataques: Milene Domingues é a mãe de seu filho; Nádia e Viviane tornaram-se artistas; Suzana Werner casou com um outro jogador (ou seja, teve sucesso em encontrar um jogador de futebol em uma carreira que ela começou com ele); e Lívia Lemos ganhou uma capa de Playboy. Em resumo, tanto as fotos como as legendas, por meio de índices de referência e de predicação (WORTHAM, 2001), intensificam a performance de Ronaldo como um matador de mulheres que não só pediram tal tratamento mas também tiveram vantagens por causa dele. Um outro elemento que acentua a narrativa de Ronaldo como performance é sua estrutura paralela (BAUMAN, 1977) por meio: a) de como as fotos estão temática e graficamente organizadas na página; e b) de como a sintaxe nas legendas está estruturada.

Até agora a análise dos posicionamentos somente se baseou no título da narrativa, nas fotos e nas legendas. Esses elementos já enunciam a 
performance narrativa da masculinidade hegemônica de Ronaldo. Cabe agora prosseguir para o texto escrito, propriamente. A sentença que segue o título da narrativa enuncia Ronaldo como o "Don Juan dos tempos modernos" e lexicamente também o posiciona como "o fenômeno fora do campo". Em tal referência, o jornalista toma emprestado uma palavra por meio da qual Ronaldo é referido como um jogador nos discursos do futebol com o propósito de descrever sua performance como um amante (tal estratégia ecoa o modo como a palavra atacante foi usada acima, ou seja, é transportada do discurso dos esportes para o discurso do amor/ sexo). Novamente tais discursos são reunidos no parágrafo 1: "Fenômeno, também, na arte da sedução. Ronaldo segue colecionando namoradas com a mesma facilidade com que dribla seus marcadores antes de fazer um gol." Essa sentença, portanto, anuncia os posicionamentos que ele ocupará em sua performance e prepara o leitor para o que vai surgir no texto escrito: uma narrativa sobre um amante irresistível.

Ecoando o que é apresentado no próprio título do artigo, Ronaldo é construído como o agente ("Don Juan dos tempos moderno, Ronaldo prova que também é um fenômeno fora do campo") e as mulheres são apresentadas como objetos de suas ações. Ele é colocado como sujeito de verbos de ação tais como coleciona, dribla, marca, elege, envolver-se, namorar etc. $\mathrm{E}$ as mulheres são posicionadas como objetos de tais verbos: namoradas, nova musa, mais um gol (metaforicamente, uma nova mulher), Rainhas das Embaixadas etc.

Em grande parte das sentenças em que as mulheres ocupam a posição de sujeito dos verbos, elas o são por causa de Ronaldo: "Livia ganhou a capa de Playboy" (está implícito que isso aconteceu pela fama que conseguiu ao namorar Ronaldo); "se envolveu num rumoroso 'affair' com a mineira Nádia França, que viria a juntar-se a paulista Viviane Brunieri para, na carona do amado, virarem celebridade"; " a namorada [...] perdeu a criança" (Ronaldo a tornou grávida); "apareceu a advogada Juliana Ferraz, revelando ao mundo ser uma amante de 10 anos do astro a ponto de ter se submetido a dois abortos de filhos do Fenômeno", "declarou que não gostaria de ter o brasileiro como vizinho"; "Mireia Canalda chegou a flertar com Ronaldo"; "a única que afirma ter resistido foi a apresentadora de TV Fernanda Lima”.

É interessante notar que Ronaldo é posicionado como um amante "cobiçado" por todas as mulheres que povoam a narrativa, com exceção de uma: Fernanda Lima. Ela, contudo, aparece no final da narrativa (ou seja, na lista das amantes) e estrategicamente sua foto ocupa o canto esquerdo mais 
inferior da página de modo a minimizar sua importância. No texto escrito, a inclusão dessa última amante funciona como uma avaliação final e coda da narrativa (LABOV, 1972), com a qual a estória fecha: "Será" que existe tal mulher que poderia resistir aos encantos desse Don Juan moderno? Essa avaliação/coda na qual o narrador se dirige diretamente ao leitor ("Será?") parece ser a razão pela qual a narrativa foi contada ou constitui o ponto da narrativa.

Um último aspecto se relaciona à referência que é feita a Ronaldo como "Sinônimo de projeção social" (parágrafo 3), como um homem que é "Cobiçado, por ser famoso e milionário" (parágrafo 6), e como "sonho de consumo de muitas 'donzelas" (parágrafo 6). Note que a palavra donzelas aparece entre aspas, o que implica que as mulheres são, de fato, prostitutas que vendem seus corpos por dinheiro. Ronaldo é consequentemente construído como um alvo para todas essas mulheres, que estão à procura de seu dinheiro e que desejam ter um filho seu de modo a levar a efeito um bom negócio. Nesse sentido, é notável que duas de suas ex-amantes são narradas como tendo prosseguido em suas carreiras de amantes de jogadores de futebol depois de Ronaldo ("Nádia, [...] hoje, mulher do atacante Alex Alves, do Vasco", parágrafo 3; e "Suzana Werner (atualmente, senhora Júlio César)", parágrafo 4). Tal narração as posiciona como mulheres que estão à procura do dinheiro de jogadores de futebol e que tiveram sucesso. Mais uma vez, os discursos do amor/sexo, esportes e negócio são colocados em diálogo.

Ronaldo é apresentado como tendo engravidado três mulheres: "Nádia [...] perdeu a criança" (parágrafo 3); "o filho Ronald nasceu em abril de 2000" (parágrafo 5); "Juliana Ferraz, [...] a ponto de ter se submetido a dois abortos de filhos do Fenômeno" (parágrafo 5). Esse posicionamento do "matador" intensifica sua performance narrativa como um homem viril assim como sua consequente incontinência sexual ("só não foi pai no início da carreira porque a namorada [...] perdeu a criança”, parágrafo 3). Ou, como diz o jornalista no parágrafo 2 , avaliando ironicamente a performance narrativa sexual do astro: "O amor é lindo, mas para o astro, dura pouco".

\section{POSICIONAMENTOS MASCULINOS EM RELAÇÃO À PERFOR- MANCE NARRATIVA DE RONALDO: UMA ENTREVISTA DE GRUPO FOCAL}

Nesta seção, com o objetivo de ampliar a dimensão da prática discursiva da análise acima, vou examinar como dois homens se posicionam ao conversar sobre a performance narrativa de Ronaldo em uma entrevista de 
grupo focal. Os participantes são dois estudantes universitários (Antonio e Victor), com idades de 24 e 42 anos, respectivamente. São leitores familiarizados com $O$ Dia e especificamente com a seção de esportes do jornal, intitulada Ataque, sendo, portanto, membros da comunidade de leitores projetada do jornal. Ambos se apresentaram como voluntários e lhes disse que estava interessado no que tinham a dizer sobre o artigo. A entrevista foi realizada na sala de nosso projeto na UFRJ, durante uma hora, depois que os leitores leram a matéria. Sentamos em volta de uma mesa na qual havia dois gravadores e começamos a discutir o texto. Para ilustrar os resultados da análise, selecionei a transcrição de três sequências da entrevista de uma hora que indicam os posicionamentos desses dois rapazes. Tais posicionamentos mobilizam significados tradicionais sobre a masculinidade na direção dos posicionamentos disponibilizados na performance narrativa de Ronaldo como mostrado acima e localmente apoiam os posicionamentos interacionais de um em relação ao outro assim como em relação a mim como membros de uma comunidade imaginada de masculinidade hegemônica (MOITA LOPES, 2001 e 2006b).

$\mathrm{Na}$ análise dos dados, adotei os seguintes procedimentos. Primeiro, li toda a entrevista transcrita para ter uma compreensão geral. A seguir, codifiquei os dados com base nos "arcabouços topicais" (BROWN; YULE, 1983: 73) em relação a como os participantes definiam os sentidos de que o texto tratava. Nesse procedimento, separei as interações relacionadas a cada arcabouço topical. Por fim, empreendi uma análise das interações relacionadas a como os participantes se posicionaram interacionalmente em relação à performance narrativa de Ronaldo e em relação aos outros participantes masculinos do evento.

Sequência 1: Abertura: construindo pertencimento ao grupo masculino ${ }^{3}$

1 LP: Então,/ o que vocês acharam?//

$2 \mathrm{~V}$ : $\mathrm{Na}$ época em que essa reportagem foi publicada,/ ela foi bastante comentada.//

$3 \mathrm{Na}$ rua,/ nos bares./

$4 \mathrm{LP}: \mathrm{Ah}, \mathrm{e}$ ?//

$5 \mathrm{~V}$ : Eu lembro bem dessa reportagem, na época.//

\footnotetext{
${ }^{3} \mathrm{Na}$ transcrição, utilizei as seguintes convenções: / para pausa curta, // para pausa longa, [ ] para comentário do autor, [...] para omissão de texto, ( ) para incluir texto esclarecendo o que está sendo dito.
} 
6 LP: E você lembra, A?//

7 A: Não, não.//

8 LP: Você tinha lido?//

9 A: Não, acho que não.//

10 LP: Você tinha.//

$11 \mathrm{~V}$ : Então, se falava muito em Ronaldinho/ fenômeno/ nessa ocasião e//

12 LP: Que ele é fenômeno e tudo,/ né?//

$13 \mathrm{~V}$ : Exatamente./ E justamente nessa época/ ele já era chamado de fenômeno/

e isso aqui

14 ganhou notoriedade em função dessa/ éhh/ digamos/ certa facilidade que ele tinha

$15 \mathrm{em} /$ trocar de namorada//

16 LP: Facilidade, é?//

17 [Risos]

$18 \mathrm{~V}$ : Certa facilidade./ E/ a gente sabe que no Brasil/ os jogadores de futebol já de fama

19 reconhecida e já com uma certa projeção/ social/ costumam ser bastante badalados/ no

20 que diz respeito a mulheres bonitas./ E o Ronaldo chamou atenção nessa ocasião pelo

21 fato de as loiras,/ geralmente serem//

A entrevista abre com meu questionamento sobre o que os participantes tinham achado do artigo. $\mathrm{V}$ se posiciona como leitor do jornal, que havia na verdade lido o artigo antes, indicando acesso epistêmico (WORTHAM, 2001) aos significados que a matéria trouxe à tona então ao dizer que "Na época em que essa reportagem foi publicada,/ ela foi bastante comentada.// Na rua,/ nos bares./" (linha 2-3) e que ele "lembr[ava] bem dessa reportagem, na época" (linha 5). Isso significa que ele foi “interpelado" pelos significados que a narrativa evocou quando foi publicada. Para apoiar sua posição, V se refere ao mundo público, se posicionado como um homem das "ruas" e dos "bares", contextos que são bem típicos das sociabilidades masculinas no senso comum. A, por outro lado, aponta que não tinha lido o artigo (linha 7) e é momentaneamente posicionado do lado de fora desse evento de leitura em particular ou fora dessa comunidade interpretativa (BRICEHEATH, 1983), que está começando a ser construída. Como consequência, a abertura é discursivamente dominada por $\mathrm{V}$, que continua a chamar a atenção para o fato de que sabe do que trata o texto, trazendo à tona o tópico discursivo (BROWN; YULE, 1983), que será focalizado de agora em diante, ou seja, como é fácil para Ronaldo conquistar mulheres, o que 
também o torna um fenômeno nessa área: "Exatamente./ E justamente nessa época/ ele já era chamado de fenômeno/ e isso aqui ganhou notoriedade em função dessa/ éhh/ digamos/ certa facilidade que ele tinha em/trocar de namorada/" (linhas 13-15).

Quando enfatizo e questiono o uso que $\mathrm{V}$ faz da palavra facilidade, meu comentário é respondido com riso por parte dos dois participantes (linha 17), o que demonstra que os participantes sinalizam seu pertencimento ao grupo dos homens. O riso aqui indica que como homens sabem que estou fazendo uma piada sobre a facilidade que Ronaldo tem em conquistar mulheres. Isso na verdade é confirmado pelo comentário de $\mathrm{V}$ nas linhas 1821: "Certa facilidade./ E/ a gente sabe que no Brasil/ os jogadores de futebol já de fama reconhecida e já com uma certa projeção/ social/ costumam ser bastante badalados/ no que diz respeito a mulheres bonitas./ E o Ronaldo chamou atenção nessa ocasião pelo fato de as loiras,/ geralmente serem//". $\mathrm{V}$ se posiciona e nos posiciona como homens conversando sobre mulheres, que estão à procura de jogadores de futebol. O riso é usado durante toda a entrevista para indicar pertencimento ao grupo masculino, o que orienta os posicionamentos que os participantes ocupam.

Sequência 2: A narrativa sobre Maria Chuteira: posicionando as mulheres

22 LP: E você,/ Antônio?// O que você acha?// O que te chamou atenção,/ nessa matéria?//

23 A: Bom,/ o que me chamou atenção primeiro foi que deu mais espaço às fotos do

24 que a matéria em si,/ né?//

25 LP: É.//

26 A: Quer dizer,/ chama muito atenção,/ a matéria em si chama muito atenção/ mas

27 muito por causa das mulheres que estão aqui,/ né?//

28 LP: As mulheres.//

29 A: A mulherada, é verdade.// E é interessante porque hoje em dia,

30 / normalmente nem precisa ser muito famoso,/ né?// Se você vai/, assim,/ eu tenho uma

31 amiga da faculdade,/ que tem uma amiga e eu conheço essa pessoa mesmo,/ que ela

32 assim, ela é maria-chuteira,/ né?/ porque isso aqui se chama maria-chuteira,/ né?/, quer

33 dizer, casa com jogador de futebol/, enfim.// E ela ia a todos os treinos do Flamengo// 
34 LP: A garota?/ Amiga dela?//

35 A: É./ E, enfim,/ ela ficou com um monte desses jogadores,/ jogador sem expressão

36 ainda,/ jogador que a gente vaia em campo,/ jogadores até desconhecidos,/ que nem

37 chegavam a ser profissionais.// [...] Ela me contou e tudo.// Quer dizer,/ foi falando

38 assim e tudo,/ né?/ que certos jogadores que nem eram, assim, reconhecidos e tal, que.

39 em cima mesmo,/ não era só ela não,/ que não era só uma garota lá,/ eram várias,

40 / entendeu?// Porque jogador de futebol,/ é aquela história,/ né?/ jogador hoje tem,/ não

41 sei,/ 18, 19 anos./ Ele/ já/. já tem contrato com o time,/ tem não sei o que,/ tem dinheiro,

42 / tem empresário,/ né?/, que já promete vai levar ele pra Itália,/ pra Espanha,/ pra onde

43 quer que seja./ Então,/ o que acontece é que essas garotas já,/ né?/ assim que pode

44 engravida, e se tomar um chute depois,/ tá lá com a criança,/ né?/, pra poder//

45 LP: Aliás,/ a matéria fala um pouco disso.//

46 A: Fala,/ é,/ falou da Milene [...]//

47 LP: Acho que tem outra também,/ que também acho tentou ter filho dele,/ quer dizer,/

48 ter filho dele,/ é uma boa por isso que você falou,/ né?//

49 A: Financeiramente,/ com certeza//

50 LP: (Essa outra) foi amante dele,/ é?// Ah,/ e aqui,/ dois abortos,/ tá vendo,/ quer dizer,

51 / que essa aí fez aborto.//

52 A: Provavelmente por pressão dele,/ né?/, se é que se confirma,/ né?/, pode ter sido por

52 pressão dele//

Quando me viro para $\mathrm{A}$, que até então estava ouvindo a conversa, e pergunto o que chamou a atenção dele no artigo, A imediatamente se posiciona como um homem heterossexual, que como tal já tinha notado as fotos das mulheres na página: "a matéria em si chama muito atenção/ mas muito por causa das mulheres que estão aqui,/ né?” (linhas 26-27). A referência a essas fotos indexicaliza seu posicionamento como um homem heterossexual. A oportunidade de participação se transforma em 
espaço para que A, o interlocutor mais jovem do grupo (e que até então estava fora da comunidade interpretativa), se posicione, indicando seu pertencimento ao universo masculino. De agora em diante, A vai dominar a conversa. Deixando claro que sabe sobre o que vamos falar e acentuando seu pertencimento ao grupo, A conta uma história, que confirma o que está dizendo. Ao narrar a história sobre uma Maria Chuteira, está performando a masculinidade hegemônica ao mostrar como se posiciona em relação à performance de Ronaldo, aos personagens de sua própria narrativa e aos participantes do grupo, já que a narrativa de A realiza o que articula (linhas 30-44).

Enquanto sua narrativa intensifica sua performance como homem, também aumenta seu acesso epistêmico ao que está sendo discutido: ele experienciou um fato, que ilustra a conversa: "Ela me contou e tudo.// Quer dizer,/ foi falando assim e tudo,/ né?/" (linhas 37-38). A história é sobre uma amiga dele que tem uma amiga, que ele conhece e que é uma Maria Chuteira. Ela é predicada como tal por que está à procura do dinheiro de jogadores de futebol. Consequentemente, nas palavras de A, elas estão sintaticamente colocadas como sujeito de verbos que chamam a atenção para suas ações com o objetivo de atrair jogadores de futebol: "E ela ia a todos os treinos do Flamengo" (linha 33); "ela ficou com um monte desses jogadores" (linha 35); "essas garotas já,/ né?/ assim que pode engravida" (linhas 43-44).

Da mesma forma que na análise do jornal acima, os jogadores ou são objeto das ações das mulheres ou são descritos como tendo o que elas procuram: "Ele/ já/. já tem contrato com o time,/ tem não sei o quê,/ tem dinheiro,/ tem empresário,/ né?" (linhas 41-42). Contudo, A acrescenta que se os jogadores as descartarem, elas não se importam, por que já têm o que procuram: uma gravidez ou um filho ("Então,/ o que acontece é que essas garotas já,/ né?/ assim que pode engravida, e se tomar um chute depois,/ tá lá com a criança,/ né?/, pra poder//" (linhas 43-44). Os itens lexicais em "tomar um chute" indexicalmente posicionam tais mulheres como pessoas que podem ser descartadas e jogadores como pessoas que podem descartálas já que elas podem ser compradas e jogadas fora quando não mais necessárias. Essa narrativa sintetiza o que vai acontecer nas linhas seguintes e claramente espelha os posicionamentos identificados na performance narrativa de Ronaldo. O ponto de A é ainda mais sublinhado nas linhas 49 e 52 quando acrescenta dois comentários avaliativos à narrativa que 
acabou de contar: "Financeiramente,/ com certeza (é boa ideia ter um filho dele)" (linha 49) e "(Ela teve dois abortos) Provavelmente por pressão dele,/ né?/” (linha 52). Conforme indicado na análise da performance narrativa de Ronaldo, os discursos de amor/sexo e negócio estão também em diálogo nessa conversa sobre o texto e nas performances de masculinidade hegemônica por ela engendradas.

Sequência 3: Posicionando Ronaldo como um "matador" e as mulheres como beneficiárias de suas práticas sexuais

60 LP: Agora,/ e por que se chama matador,/ né?/, engraçado,/ né,/ quem é o 61 matador,/ né?//

62 A: Pois é, né?/ Tem um duplo sentido aí,/ né?/ porque matador é o atacante que faz gol,

63 / né?//

64 LP: No futebol chama matador também,/ é?//

$65 \mathrm{~A}: \mathrm{E}, /$ no futebol,/ chama matador//

66 LP: O toureiro também é matador,/ engraçado,/ né?/ Vi isso na Espanha/ e eu não sabia

67 que chamava no esporte matador./ Então,/ por que você acha que é matador?/ É

68 engraçado isso,/ né?//

69 A: É,/ né?/ é como se fosse,/ na verdade,/ é como se ele levasse pra cama pra matar.//

70 LP: Pra matar as mulheres//

71 A: Deixa eu ver aqui,/ aqui vai falando também da Daniela Cicarelli,/ né?/ Você vê que é

72 tudo famosa,/ antes de conhecer a maioria não era famosa,/ como no caso dessas aqui.//

73 LP: As outras não eram?//

$74 \mathrm{~A}: \mathrm{E}, /$ né?//, e essa Milene,/ se eu não me engano era jogadora de futebol,/ era a rainha

75 das embaixadinhas,/ e tudo,/ diziam que fazia embaixadinha e depois que ficou grávida

76 dele virou a rainha das embuchadinhas.//

77 [Risos]

78 LP: E aí ficaram famosas,/ né?//

79 A: É o status,/ né?/ quer dizer//

80 LP: Quer dizer,/ passar pela cama com esse cara é bom.//

81 V: Valoriza o cachê delas.// 
Pergunto a eles sobre o título do artigo, "matador", que é um elemento chave nos significados que identifiquei na performance narrativa de Ronaldo, e A imediatamente torna clara a ambiguidade envolvida na escolha desse item lexical. Indica que tal palavra é usada para mobilizar discursos do mundo do futebol ("A: Pois é, né?/ Tem um duplo sentido aí,/ né?/ porque matador é o atacante que faz gol,/ né?//" (linhas 62-63), e os discursos de um ato sexual ("A: É,/ né?/ é como se fosse,/ na verdade,/ é como se ele levasse pra cama pra matar.//" (linha 69). O uso metafórico da palavra matar como um substituto para "fazer sexo" parece alinhar A aos posicionamentos disponibilizados na performance de Ronaldo, o que leva A a posicionar as mulheres como beneficiárias do "matador".

Os itens lexicais que A utiliza para predicar as mulheres indexicalizam como ele interacionalmente as posiciona na performance narrativa de Ronaldo e em relação aos homens que participam da entrevista: as mulheres "ficam famosas" e adquirem "status" depois de fazerem sexo com ele. Em apoio a esse argumento, A ainda encaixa em seu enunciado uma rápida história que ecoa o que as pessoas dizem sobre Milene e como ela se transformou de "rainha das embaixadinhas" para "rainha das embuchadinhas". Os discursos do sexo, do amor e dos negócios são construídos como sinônimos aqui e desenvolvidos a partir da primeira história que A contou sobre a Maria Chuteira. A avaliação final dessa última narrativa é enunciada em: "(ir para cama com Ronaldo) Valoriza o cachê delas" (linha 81).

\section{PALAVRAS FINAIS: A CONGRUÊNCIA DOS EFEITOS DISCURSIVOS}

As análises mostram que os posicionamentos de Ronaldo na performance narrativa de masculinidade hegemônica, conforme a análise crítica multimodal do discurso indica, são refletidos nos posicionamentos interacionais que os dois participantes do grupo focal adotam em relação um ao outro, em relação a mim como entrevistador, em relação a Ronaldo e às mulheres que povoam suas performances narrativas assim como em relação às narrativas que os participantes contam. Ambas as análises mostram como os posicionamentos interacionais movimentam discursos que dão apoio a performances de masculinidade hegemônica de senso comum. Isso não quer dizer, não obstante, que outros participantes na conversa sobre o texto, no grupo focal, necessariamente ocupariam os mesmos posicionamentos interacionais, nem que esses mesmos participantes, em outras práticas situadas, não se envolveriam com outros posicionamentos, tornando outras 
performances possíveis. ${ }^{4} \mathrm{Tem}$ sido argumentado, nesse sentido, na pesquisa sobre mídia, que as audiências se apropriam de discursos tanto de forma reprodutora como transformadora (CHOULIARAKI; FAIRCLOUGH, 1999: 45), já que os leitores/telespectadores etc. nunca são iguais nem permanecem iguais, ou seja, têm histórias diversas de vida, ideologias e valores, que se modificam em períodos e em espaços diferentes.

Todavia, em um mundo simbólico (não só midiático como também religioso e educacional, por exemplo) cada vez mais voltado para nichos de clientes específicos, não é de surpreender que nos deparemos com a congruência de significados que as duas análises tornam visível. De algum modo, seria possível dizer que a sociedade, de forma oblíqua ou indireta, age sobre a mídia e não somente o contrário, como tradicionalmente temos pensado. A mídia opera com os significados que vão provocar os efeitos discursivos nos quais seus leitores projetados específicos querem se engajar. Assim, o que a entrevista de grupo focal indica, como uma prática discursiva situada, é que participantes que podem ser descritos como membros do grupo de leitores projetados de O Dia parecem reproduzir os posicionamentos que o artigo disponibiliza.

Esta pesquisa mostra, portanto, que os discursos midiáticos estão devolvendo para os grupos a que se dirigem aquilo que tais grupos tradicionalmente assumem como "verdade": nesse caso, visões muito essencializadas das mulheres e dos homens, apresentados em papéis muito estereotipados, nos quais as mulheres estão à procura do dinheiro dos homens e esses as descartam depois de usá-las e de pagar por seus préstimos: uma lógica que limita os significados possíveis de serem atribuídos aos homens e as mulheres. Dessa maneira, a performance narrativa de Ronaldo parece ter um valor icônico para o grupo a que se destina, pois ajuda a organizar, solidificar e cristalizar discursos tradicionais sobre a masculinidade hegemônica já presentes no grupo de leitores projetados, uma vez que

\footnotetext{
${ }^{4}$ Que posicionamentos interacionais, por exemplo, seriam suscitados desses mesmos participantes na leitura desta narrativa agora que outras performances de masculinidade de Ronaldo, amplamente divulgadas na mídia, o mostraram em um motel com três travestis? Foi notável, porém, naquela época um empenho da parte da chamada grande mídia em tentar justificar como Ronaldo foi enganado, pois havia pensado que as três eram, de fato, mulheres biológicas: uma justificativa que, na verdade, confirma sua masculinidade hegemônica como performance. Aliás, cabe lembrar aqui a epígrafe acima que chama atenção para o fato de que, apesar da naturalização dos gêneros na mídia, com o passar do tempo se percebem os gêneros na própria mídia como performances (GAUNTLETT, 2005).
} 
performances são pelas e para as audiências. Essa performance é avaliada pelos posicionamentos interacionais dos participantes do grupo focal, que iconicamente encenam, em última análise, suas próprias performances de masculinidade no grupo, posto que, da mesma forma, performances existem pelas e para as audiências.

Esses discursos, entretanto, contradizem a heterogeneidade das performances de gênero que estão cada vez mais visíveis na vida contemporânea devido aos movimentos sociais feministas, gays e lésbicos e à miríade de discursos aos quais muitos de nós somos continuamente expostos, inclusive na mídia, e que abrem nossos horizontes para histórias diferentes sobre quem podemos ser ao nos depararmos com a fluidez e nuances da sexualidade, com a desnaturalização dos gêneros e das sexualidades e com os atravessamentos das fronteiras entre os gêneros que questionam um mundo de estereótipos. Tais discursos apresentam uma outra lógica para a pragmática de nossas vidas generificadas e para nossos desejos e que a mídia, devo enfatizar, também faz circular.

A frequência com a qual tais discursos homogêneos sobre os gêneros têm sido enunciados em O Dia, como minha pesquisa (MOITA LOPES, 2006b) tem mostrado, nos coloca, no entanto, o desafio de possibilitar que os leitores, telespectadores etc. tenham acesso a uma educação midiática que possa familiarizá-los com a variabilidade de discursos, fora de seus nichos de consumo, e principalmente com os modos de funcionamento da mídia. (E aqui tenho que enfrentar a dificuldade de escapar da compreensão de educação também como nicho de consumo!). Embora Braga (2006: 39), em um livro instigante, argumente que a sociedade tem-se organizado para enfrentar a mídia, "retrabalhando o que circula" e "desenvolvendo uma série de ações sobre a mídia - contrapositivas, interpretativas, proativas, corretoras de percurso, controladoras, seletivas, polemizadoras, laudatórias, de estímulo, de ensino [etc.]", sou de opinião que a escola brasileira não tem normalmente tomado diretamente para si a compreensão desses processos.

A educação midiática pode possibilitar a desestabilização de horizontes fechados e normalizadores da vida social ao focalizar a grande variabilidade de veículos midiáticos e seus significados, capitalizando em cima das contradições da mídia contemporânea. Acho pouco provável que um mundo que é um grande bazar material e simbólico, dividido em nichos midiáticos e seus consumidores, venha a ter veículos que apresentem de forma predominante e enfática performances narrativas de gêneros e sexualidades que contradigam as expectativas do público e que possam 
problematizar visões essencializadas dos gêneros e das sexualidades, confundindo ou embaralhando o binarismo que os essencializa e naturaliza (BUTLER, 1990).

Em tempos de heterogeneização, de fluidez, de questionamento de sociabilidades naturalizadas, e de atravessamentos de fronteiras físicas, culturais e sexuais, considero que uma das agendas principais de nossas vidas está relacionada à possibilidade de acesso a outras performances narrativas que engendrem a descoberta de outros modos de ser para além, portanto, daquelas performances naturalizadas que simplesmente espelhem o que já somos ou que somente iconicizem nossas práticas. Esse é um desafio de nossos dias saturados por textos ou densamente semiotizados, que têm o potencial de ampliar nossos repertórios de sentidos (um horizonte epistêmico promissor), os quais demandam que façamos escolhas de significados que, em última análise, não causem sofrimento - um requisito ético crucial da vida contemporânea (MOITA LOPES, 2006d). Tal horizonte me parece possível no entrecruzar de veículos midiáticos, dos discursos e das performances que fazem circular: uma posição especialmente importante se concordarmos que o que importa não é o que somos, mas o que podemos ser. Imaginar outros futuros possíveis para as nossas vidas deve ser uma preocupação da pesquisa no campo aplicado que focaliza as relações entre linguagem e práticas sociais. 


\section{ANEXO}

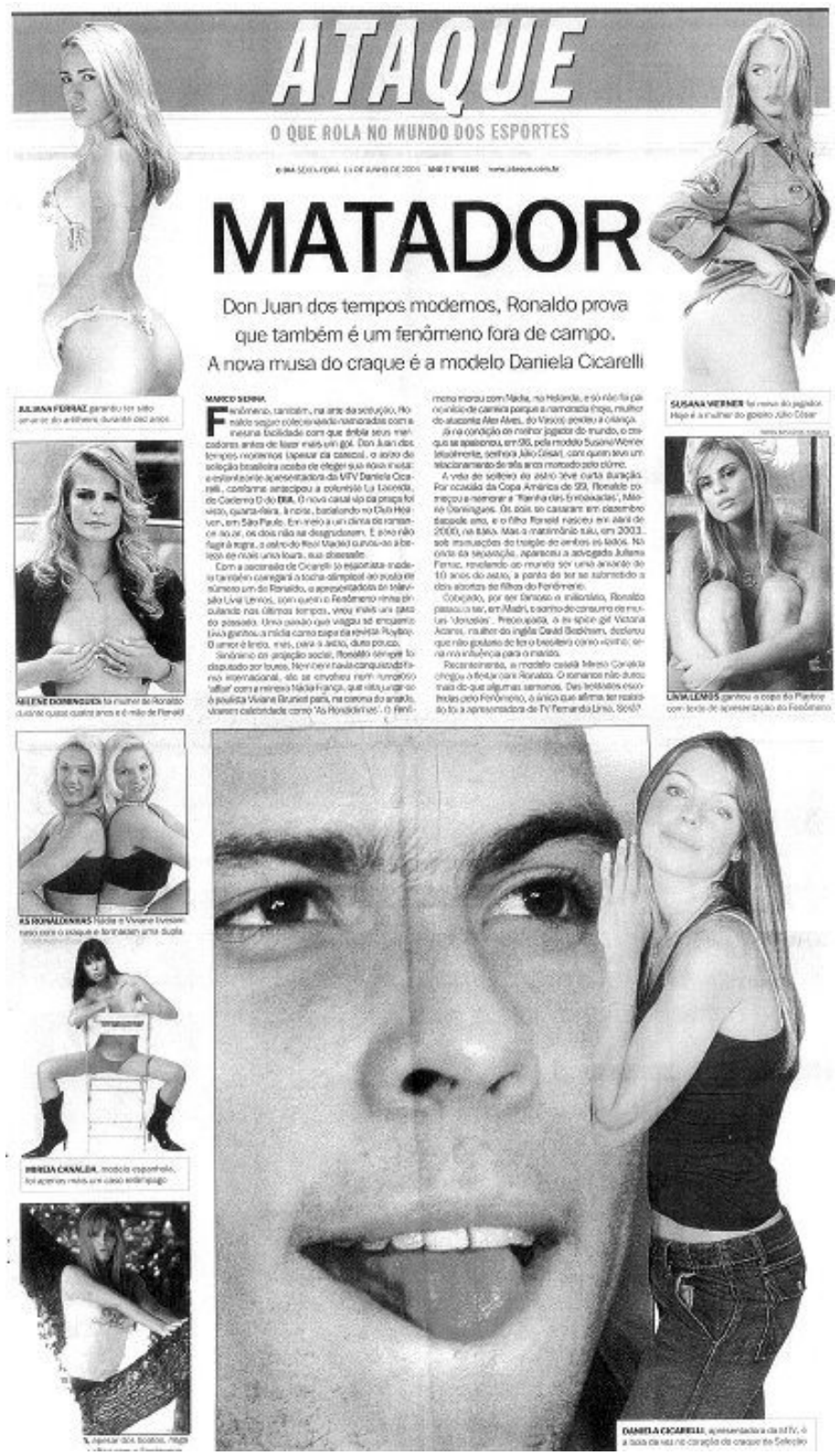




\section{REFERÊNCIAS BIBLIOGRÁFICAS}

AUSTIN, John. How to Do Things with Words. Cambridge, M.A.: Harvard University Press, 1962.

BAUMAN, Richard. Story, Performance and Event: Contextual Studies of Oral Narrative. Cambridge: CUP, 1986.

BAUMAN, Richard. Verbal Art as Performance. Prospect Heights, IL: Waveland, 1977.

BAUMAN, Zygmunt. Globalização. Rio de Janeiro: Zahar, 1999.

BELL, Allan; GARRETT, Peter. Approaches to Media Discourse. Oxford: Blackwell, 1998.

BRAGA, José L. A sociedade enfrenta sua mídia. São Paulo: Paulus, 2006.

BRICE HEATH, Shirley. Ways with Words. Cambridge: CUP, 1983.

BROWN, Gillian; YULE, George. Discourse Analysis. Cambridge: CUP, 1983.

BRUNER, Jerome. Atos de significação. Porto Alegre: Artes Médicas, 1997.

BUTLER, Judith. Bodies that Matter. Nova York: Routledge, 1993.

BUTLER, Judith. Gender Trouble: Feminism and the Subversion of Identity. Nova York: Routledge, 1990.

BUTLER, Judith. Undoing Gender. Nova York: Routledge, 2004.

CHOULIARAKI, Lily; FAIRCLOUGH, Norman. Discourse in Late Modernity. Edinburgh: Edinburgh University Pres, 1999.

CONNEL, Robert W. The Men and the Boys. Berkeley: California University Press, 2000.

COUPLAND, Nikolas; GARRETT, Peter; WILLIAMS, Angie. Narrative demands, cultural performance and evaluation: teenage boys' stories for their age peers. In: THORNBORROW, Joanna; COATES, Jennifer (Ed.). The Sociolinguistics of Narrative. Amsterdam: John Benjamins, 2005. p. 67-88. 
DAVIES, Bronnyn; HARRÉ, Rom. Positioning and Personhood. In. HARRÉ, Rom; VAN LANGENHOVE, Luk (Ed.). Positioning Theory. Oxford: Blackwell, 1999. p. 32-52.

DEBORD, Guy. A sociedade do espetáculo. Trad. Estela dos Santos Abreu. Rio de Janeiro: Contraponto, 1997.

EPSTEIN, Deborah; JOHNSON, Richard. Schooling Sexualities. Buckingham: Open University Press, 1998.

FABRÍCIO, Branca; MOITA LOPES, Luiz Paulo. Discursos e vertigens: identidades em xeque em narrativas contemporâneas. Veredas, v. 4, n. 2, p. 19-42, 2004.

FABRÍCIO, Branca; MOITA LOPES, Luiz Paulo. Práticas discursivas multimodais na sala de aula: novas sociabilidades de gênero e sexualidade. In: SIMPÓSIO NACIONAL DISCURSO, IDENTIDADE E SOCIEDADE, 2. Rio de Janeiro: PUC-Rio, 2006.

FAIRCLOUGH, Norman. Discourse and Social Change. Cambridge: Polity Press, 1992.

FAIRCLOUGH, Norman. Media Discourse. Londres: Edward Arnold, 1995.

FOUCAULT, Michel. História da sexualidade 1: a vontade de saber. Trad. Maria Tereza Albuquerque e J. A. Albuquerque. Rio de Janeiro: Graal, 1988/2001.

FOUCAULT, Michel. Microfísica do poder. Trad. Roberto Machado. São Paulo: Graal, 1979.

GAUNTLETT, David. Media, Gender and Identity. An Introduction. Londres: Routledge, 2005.

GIDDENS, Anthony. Mundo em descontrole: o que a globalização está fazendo de nós. Trad. Maria Luiza X. de A. Borges. Rio de Janeiro: Record, 2000.

GIDDENS, Anthony; BECK, Ulrich; LASH, Scott. Modernização reflexiva. Trad. Magda Lopes. São Paulo: Editora da UNESP, 1997. 
GOFFMAN, Erving. The Presentation of Self in Everyday Life. Garden City, NY: Anchor Books, 1959.

HARRÉ, Rom; VAN LANGENHOVE, Luk (Ed.). Positioning Theory. Oxford: Blackwell, 1999.

KRESS, Gunther; VAN LEEUWEN, Theo. Multimodal Discourse. The Modes and Media of Contemporary Communication. Nova York: OUP, 2001.

KULLICK, Don. No. Language and Communication, v. 23, p. 139-151, 2003.

LABOV, William. Language in the Inner City. Philadelphia: University of Philadelphia Press, 1972.

LANGELLIER, Kristin M. 'You're Marked'. Breast Cancer, Tattoo, and the Narrative Performance of Identity. In: BROCKMEIER, Jens; CARBAUGH, Donald (Ed.). Narrative and Identity: Studies in Autobiography, Self and Culture. Amsterdam: John Benjamins Publishing Co, 2001. p. 145-184.

LITOSSELITI, Lia. Using Focus Groups in Research. Londres: Continuum International Publishing Group, 2003.

LOURO, Guacira L. Gênero, sexualidade e educação. Uma perspectiva pós-estruturalista. Petrópolis: Vozes, 1997.

MARTIN, Jim R. Positive Discourse Analysis: Solidarity and Change. [mimeo, s/d.].

MARTIN-BARBERO, J. (1987). Dos meios às mediações. Comunicação, cultura e hegemonia. Rio de Janeiro: Editora da UFRJ, 2003.

MOITA LOPES, Luiz Paulo (Org.). Discursos de identidades. Campinas: Mercado de Letras, 2003.

MOITA LOPES, Luiz Paulo (Org.). Por uma lingüística aplicada indisciplinar. São Paulo: Parábola, 2006d.

MOITA LOPES, Luiz Paulo. 'Falta homem até pra homem': a construção da masculinidade hegemônica no discurso midiático. In: HEBERLE, Viviane; OSTERMANN, Ana; FIGUEIREDO, Deborah (Org.). Linguagem e gênero. Florianópolis: Editora da UFSC, 2006b. p. 131-157. 
MOITA LOPES, Luiz Paulo. Discurso, corpo e identidade: masculinidade hegemônica como comunidade imaginada na escola. Gragoatá UFF, v. 11, p. 207-226, 2001.

MOITA LOPES, Luiz Paulo. Identidades fragmentadas. Campinas: Mercado de Letras, 2002.

MOITA LOPES, Luiz Paulo. On Being White, Male and Heterosexual: Multiple Positionings in Oral Narratives. In: DE FINA, Anna; SCHIFFRIN, Deborah; BAMBERG, Michael (Ed.). Discourse and Identity. Cambridge: CUP, 2006c. p. 288-313.

MOITA LOPES, Luiz Paulo. Queering Literacy Teaching: Analyzing Gay-Themed Discourses in a Fifth-Grade Class in Brazil. Journal of Language, Identity and Education, v. 5, n. 1, p. 31-50, 2006a.

MOITA LOPES, Luiz Paulo; DURÃO, Fábio; ROCHA, Roberto (Org.). Performances. Rio de Janeiro: Contra-capa, 2007.

MOITA LOPES, Luiz Paulo; FABRÍCIO, Branca F. Discurso como arma de guerra: um posicionamento ocidentalista na construção da alteridade. DELTA, v. 21, n. especial, p. 239-285, 2005.

MORGAN, David; KRUEGER, Richard. The Focus Group Kit. Thousand Oaks, Ca.: Sage, 1998. 6 v.

NORRICK, Neal R. Contextualizing and Recontextualizing Interlaced Stories in Conversation. In: THORNBORROW, Joanne; COATES, Jennifer (Ed.). The Sociolinguistics of Narrative. Amsterdam: John Benjamins, 2005. p. 107-128.

SARANGI, Srikant. Discourse Practitioners as a Community of Interprofessional Practice: Some Insights from Health Communication Research. In: CANDLIN, Christopher N. (Ed.). Research and Practice in Professional Discourse. Hong Kong: City University of Hong Kong Press, 2002. p. 95-135.

SHIFFRIN, Deborah. Narrative as self-portrait: sociolinguistic constructions of identity. Language in Society, v. 25, p. 167-203, 1996.

THOMPSON, John B. A mídia e a modernidade. Uma teoria social da mídia. Trad. Wagner de Oliveira Brandão. Petrópolis: Editora Vozes, 1998. 
THORNBORROW, Joanne; COATES, Jennifer. The Sociolinguistics of Narrative, Identity, Performance, Culture. In: THORNBORROW, Joanne; COATES, Jennifer (Ed.). The Sociolinguistics of Narrative. Amsterdam: John Benjamins, 2005. p. 1-16.

THREADGOLD, Terry. Performing Theories of Narrative: Theorizing Narrative Performance. In THORNBORROW, Joanne; COATES, Jennifer (Ed.). The Sociolinguistics of Narrative. Amsterdam: John Benjamins, 2005. p. 261-278.

VAN DIJK, Teun A. Opinions and Ideologies in the Press. In: BELL, Alan; GARRETT, Peter (Ed.). Approaches to Media Discourse. Oxford: Blackwell, 1998. p. 21-63.

VAN LANGENHOVE, Luk; HARRÉ, Rom. Introducing Positioning Theory. In: HARRÉ, Rom; VAN LANGENHOVE, Luk (Ed.). Positioning Theory. Oxford: Blackwell, 1999. p. 14-31.

VAN LEEUWEN, Theo; JEWITT, Carey (Ed.). Handbook of Visual Analysis. Londres: Sage Publications, 2002.

WORTHAM, Stanthon. Narratives in Action. A Strategy for Research and Analysis. Nova York: Teachers' College Press, 2001. 